\title{
OPEN Effects of nickel content on the microstructure, microhardness and corrosion behavior of high-entropy AlCoCrFeNix alloys
}

\begin{abstract}
M. López Ríos ${ }^{1}$, P. P. Socorro Perdomo ${ }^{1}$, I. Voiculescu ${ }^{2}$, V. Geanta ${ }^{3}$, V. Crăciunn ${ }^{4,5}$, I. Boerasu ${ }^{4}$ \& J. C. Mirza Rosca ${ }^{1 凶}$

In this study the effect of three different nickel concentration on the microstructure, hardness and corrosion properties of high entropy alloys (HEAs) from AlCrFeCoNi system as an alternative material for medical instruments fabrication was investigated. The analyzed HEAs were AICrFeCoNix obtained by vacuum arc remelting from high purity raw materials and having nickel atomic ratio $x=1.0,1.4$ and 1.8. The microscopy examination revealed the dendritic morphology for the reference alloy (AlCrFeCoNi) and that the extent of the interdendritic areas increased with the concentration of nickel while $\mathrm{Cr}$ was more segregated in the interdendritic areas than in dendrites. Hardness values decreased as the percentage of nickel increased due to the dissolution of the precipitates in a nickelrich matrix and consequently the formation of continuous solid solutions. The corrosion properties of the synthesized HEAs were evaluated using a potentiodynamic polarization method. The alloys were immersed in Simulated Body Fluid during one week and the corrosion parameters were recorded. The low corrosion rates, low corrosion currents and high polarization resistance attest the good stability of these HEAs in simulated biological environment indicating their possible use for surgical and dental instruments.
\end{abstract}

Classic metallic alloys generally contain one metal in a high proportion, called the base metal, and very rarely two metals in similar proportions. Although small amounts of other elements are added, this can make a big difference in the characteristics of the obtained alloy. Due to the great advance of science and technology, new metallic alloys containing more than 2 base metals, with a different metallurgical concept, have been recently explored ${ }^{1,2}$.

High-entropy alloys (HEAs) are one of the most promising results of the exploration of new chemical compositions for metallic materials with improved performance ${ }^{3-5}$. Originally, they were defined as an alloy with at least five metallic elements with atomic percentage between 5 and $35 \%{ }^{6}$.

One of the basic alloy from HEA category, AlCoCrFeNi, was discovered in 2014 by Zhang's group at University of Science and Technology from Beijing, China ${ }^{2}$. Many other groups have joined the research effort to understand this HEA microstructure ${ }^{7,8}$, hardness ${ }^{9,10}$, strength $^{11,12}$, friction and wear ${ }^{13}$ and thermal resistance ${ }^{14,15}$ particular properties. Although many interesting topics have been explored, only few studies deal with corrosion properties of this high-entropy alloy, in general depending of fabrication method: if is synthesized by laser additive $^{16}$, by electrospark process ${ }^{17}$ and by spark plasma sintering with pre-alloy powders obtained through gas atomization $^{18}$. Other studies, with different aluminium concentration were performed ${ }^{19-21}$.

In the late last century, the progress of materials science led to the rapid development of biomedical materials. Nowadays, titanium alloys are widely used as implants and prosthesis in the human body because of their excellent biocompatibility and low density. However, titanium alloys do not have sufficient strength characteristics

${ }^{1}$ Mechanical Engineering Department, University of Las Palmas de Gran Canaria, Campus Universitario Tafira, Edif.Ingenieria, 35017 Gran Canaria, Spain. ${ }^{2}$ Faculty of Industrial Engineering and Robotics, Politehnica University of Bucharest, 313 Splaiul Independentei, 060042 Bucharest, Romania. ${ }^{3}$ Faculty of Materials Science and Engineering, Politehnica University of Bucharest, 313 Splaiul Independentei, 060042 Bucharest, Romania. ${ }^{4}$ National Institute for Laser, Plasma and Radiation Physic, Magurele, Romania. ${ }^{5}$ Extreme Light Infrastructure-Nuclear Physics, IFIN-HH, Magurele, Romania. ${ }^{\circledR}$ email: julia.mirza@ulpgc.es 
for medical instruments used for surgery or prosthetic devices. The recent development of HEAs provides a new generation of biomaterials which may can be used for medical devices.

To be able to use the high-entropy alloys for the manufacturing of medical instruments (like cutters, saws, scalpels etc.), their mechanical characteristics and corrosion resistance in physiological fluids which contain $1 \%$ wt. $\mathrm{NaCl}$, must be tested. Furthermore, if the material corrodes due to chemical attack, some corrosion products that will form can produce undesirable reactions at metal-tissue interface. To avoid this deleterious effect, the chemical composition of the new alloys must be carefully designed ${ }^{22}$. The material needs to be inert in contact with the human body, so it won't cause any metal contamination when used internally. Together with the mechanical properties ${ }^{23,24}$, corrosion resistance plays a critical role in determining the successful use of HEAs for biomedical applications ${ }^{25,26}$. In this study the effect of three different nickel concentrations on the microstructure, hardness and corrosion properties of high entropy alloys from $\mathrm{AlCrFeCoNi}$ system has been investigated. The reason for adding nickel is that nickel generally increases ductility and hardness. Nickel improves heat treatment properties by expanding the critical temperature level, it does not form oxides and this increases strength without decreasing ductility. The results presented below indicate that the structure and corrosion behavior of $\mathrm{AlCrFeCoNix}$ alloys strongly depends on the Ni content.

\section{Experimental}

Materials and samples preparation. The high entropy AlCrFeCoNix alloys (with $\mathrm{x}=1.0,1.4$ and 1.8) were obtained in the ERAMET Laboratory of the Politehnica University of Bucharest, using the MRF ABJ 900 Vacuum Arc Remelting (VAR) installation ${ }^{10,25}$. The theoretical degree of assimilation of the chemical elements during melting and the possible losses by vaporization were taken into account for designing the metallic charge. Highly pure raw materials, including $\mathrm{Al}, \mathrm{Cr}, \mathrm{Fe}$, $\mathrm{Co}$ and $\mathrm{Ni}$ (at least 99.5\%) were used. In order to obtain the adequate homogeneity, the obtained alloys were flipped and re-melted in VAR equipment for 6 times ( 3 times on each part) under inert atmosphere of Argon.

Samples in the form of rods of about $10 \mathrm{~cm}$ long and $1 \mathrm{~cm}$ diameter were obtained. The rods were transversally cut and some samples were selected for homogenization (annealing to $1100{ }^{\circ} \mathrm{C}$ for $48 \mathrm{~h}$ followed by water quenching). For structural, compositional and mechanical analyses the samples were embedded into an epoxy resin cylinder and then their surface was prepared in 3 stages: (1) polishing with $\mathrm{SiC}$ abrasive papers of progressive grain size from 240 to 2000 grit; (2) final polishing with $0.1 \mu \mathrm{m}$ alpha alumina paste; (3) cleaning in ultrasonic deionized water.

Test environment. All the measurements were performed in Ringer Grifols solution (from Grifols Laboratories, Barcelona, Spain) with the following composition in $\mathrm{mmol} / \mathrm{l}: \mathrm{Na}^{+} 129.9 ; \mathrm{K}^{+} 5.4 ; \mathrm{Ca}^{2+} 1.8 ; \mathrm{Cl}^{-} 111.7$ and $\mathrm{C}_{3} \mathrm{H}_{5} \mathrm{O}_{3}{ }^{-}$27.2. It is a modified physiological solution in which part of the sodium ions are replaced by calcium and potassium ions and parts of the chlorine ions by lactate ions. The lactate ions are transformed into bicarbonate ions allowing a regulation of the solution $\mathrm{pH}$. The tests were conducted at $37 \pm 0.1^{\circ} \mathrm{C}$ in a thermostatic bath.

Microstructural characterization. To study the microstructure of the alloys by optical microscopy, their surface was etched by electrochemical route using a solution of $10 \%$ oxalic acid, a current of $5 \mathrm{~A}$ and an immersion time of $4 \mathrm{~s}$. The observations of the surface were made using an OLYMPUS PME 3-ADL microscope.

Scanning electron microscope (SEM) observations were made using a S LoVac of the Apreo Field Emission Scanning Electron Microscope (THERMO FISHER SCIENTIFIC, Co., USA) equipped with a TEAM EDX spectrometer. For ensuring the best high vacuum imaging and analytic conditions the microscope was set to run at $20 \mathrm{kV}$ voltage and $1.6 \mathrm{nA}$ beam current, for working distance of $10.0 \mathrm{~mm}$.

Electrochemical measurements. The electrochemical measurements were made with a conventional three-electrode electrochemical cell: the sample as working electrode, Pt as counter electrode and a saturated calomel electrode (SCE) as reference electrode. The used potentiostate was a SP-150 (BioLOGIC Science Instruments) controlled by a computer with EC-LAB software package.

Open circuit potential (OCP). Open circuit potential measurements during 3 days were performed, followed by potentiodynamic polarization measurements. All tests were performed three times and data were processed using EC-LAB software.

Potentiodynamic polarization studies-polarization resistance and Tafel slopes. In order to calculate the Tafel slopes for the partial anodic processes $\left(\mathrm{b}_{\mathrm{a}}\right)$, and the Tafel slopes for the partial cathodic processes $\left(\mathrm{b}_{\mathrm{c}}\right)$, the linear polarization curves have been shifted from $\mathrm{E}_{\mathrm{OCP}}-150 \mathrm{mV}$ to $\mathrm{E}_{\mathrm{OCP}}+150 \mathrm{mV}$ using a scanning rate of $10 \mathrm{mV} / \mathrm{s}$. The polarization studies to evaluate the passivation process continued with measurements from $-800 \mathrm{mV}$ (vs. SCE) to $+500 \mathrm{mV}$ (vs.SCE), increasing the potential at a scanning rate of $1 \mathrm{mV} / \mathrm{s}$. SP-150 potentiostate was used to perform the tests and data were processed using EC-LAB software, both from BioLOGIC Science Instruments. Results showed the potentiodynamic polarization curves and the breakdown potential.

Microhardness measurements. The HEAs Vickers microhardness has been measured by an indentation test using a REMET HX-1000 Microhardness Tester. The samples, with the surfaces polished to mirror quality for good vision of the prints, were indented every $0.5 \mathrm{~mm}$ along the diameter. The tests were carried out according to the regulation UNE-EN ISO 6507-1:2006, applying a load of $100 \mathrm{~g}$ during $15 \mathrm{~s}$. A minimum of 5 
indentations were made on each sample and the average value was calculated, expressing it as the Vickers hardness (HV).

XRD analysis. X-ray diffraction experiments were performed with the aid of an empyrean diffractometer (MALVERN-PANALYTICAL). The instrument was working with a $\mathrm{Cu} \mathrm{Ka}$ anode at a power of $45 \mathrm{kV}$ and $40 \mathrm{~mA}$ in the Bragg-Brentano geometry. The samples were rotated during acquisition to ensure a better data collection. The acquired patterns were simulated to extract the crystalline phase present, lattice parameter and grain size with the aid of HighScore Plus software from MALVERN-PANALYTICAL.

\section{Results and discussions}

Microstructure. The phase structure of an alloy is critical for its biocompatibility and depends on the solubility of the alloying elements. The interaction between the phase structure and the biologic environment determines which elements will be released and, therefore, how the body will respond to the alloy. The grain size affects the corrosion processes because the grain boundaries influence the corrosion behaviour. The smaller the grain size of the samples, the higher the critical current density they will have as the edges of the grains store internal energy that promotes the corrosion ${ }^{27}$.

The microstructures of the analysed HEAs before corrosion tests are shown in Fig. 1a-f. The overall look of the optical microstructures is dendritic (Fig. 1a-c). The different concentrations of the alloying elements involves the morphology of the phases. Thus, in the case of $\mathrm{AlCrFeCoNi}$ the aspect of the dendrites is quite round, while in the $\mathrm{AlCrFeCoNi} i_{1.4}$ sample we can observe needle forms that are oriented in different directions. The $\mathrm{AlCrFeCoNi}{ }_{1.8}$ sample combines rounded phases with needle-like phases, consistent with the observation reported by Cao et al. ${ }^{28}$.

Chrome induces the formation of a protective and compact oxide layer on the surface of nickel alloys, the optimum corrosion resistance being obtained with $\mathrm{Cr}$ contents of about $16-27 \%$. If the $\mathrm{Cr}$ content is lower, the alloy may not be able to develop a passive film adequate for a good corrosion resistance. AlCrFeCoNi has a spinodal structure quite typical for high entropy alloys, as we reported before ${ }^{5}$. This structure determines the smaller dimension of the phases and higher interfaces area increasing the hardness value.

The SEM observations are presented in Fig. 1d-f. The microstructural aspect is similar to that observed by optical microscopy. In the case of $\mathrm{Ni}_{1}$ alloy, the crystalline grains with crystallites are observed, organized like Chinese letters, bordered by linear limits (Fig. 1d). As the $\mathrm{Ni}$ content increases in the $\mathrm{Ni}_{1.4}$ alloy, the appearance of acicular phases is observed (Fig. 1e). As further increase of nickel content in $\mathrm{Ni}_{1.8}$ alloy the acicular phases become rounded (Fig. 1f).

The elements $\mathrm{Al}$, Co and $\mathrm{Ni}$ can form continuous solid solutions with the same composition in the matrix of dendritic and interdendritic zones while $\mathrm{Cr}$ and Fe segregated more in the spherical precipitates of dendritic region $^{5,7}$. This suggests that the partitioning of elements from the solution phase of HEA is inherently related to the enthalpy and miscibility between the various atoms present ${ }^{22}$.

The heat treatment performed after casting promoted homogenization of chemical composition and changes of microstructure aspect (Fig. 1g-i). The linear appearance of the grain boundaries was replaced by curved connections and the amount of needle phase decreased. In Fig. $1 \mathrm{~g}$ three types of phases can be distinguished, as follows: a majority phase (light gray) with dendritic appearance, an inter-dendritic phase (dark gray) and thin needle like phase formed inside the majority phase. As the nickel concentration increased (Fig. 1h,i), there was a compositional change of the 2 major phases (dark gray and light gray) and a decreasing of the needle-like phase number.

The surface of the samples was examined also after performing heat treatment and corrosion test. For all the samples, pitting corrosion was observed. The images of the corroded surfaces highlight the acicular-looking phases that formed in the microstructure after the heat treatment (see Fig. 1j-1). It is observed how the chemical solution partially dissolved the surface film and preferentially attacked the alloy phases. As the Ni content in sample $\mathrm{Ni}_{1.8}$ increases to 31 at.\% (Fig. 11), more extended corrosion effects on the alloy phases are observed.

EDS analysis. The EDS analyses have been performed on micro-zones, having the same square area, see Fig. 1g-l. The results of the chemical composition for the three alloys are presented in Table 1.

Analyzing the EDS results from Table 1 it is observed that $\mathrm{Al}$ concentration decreases in all samples that were simultaneously heat treated and corroded, from about 10 at $\%$ to $2.57-3.03$ at $\%$. A similar evolution is observed in terms of $\mathrm{Ni}$ concentration, which decreases from the maximum values existing in the heat treated samples ( 24.99 at $\%$ for $\mathrm{Ni}_{1}$ to 37.68 at $\%$ for $\mathrm{Ni}_{1.8}$ ) to just over half of the initial values ( 12.73 at $\% \mathrm{Ni}$ for $\mathrm{Ni}_{1}$ to 25.14 at $\%$ $\mathrm{Ni}$ for $\mathrm{Ni}_{1.8}$ ). $\mathrm{Cr}$ and $\mathrm{Fe}$ maintain their concentrations within tight limits (maximum variations of 5 at $\%$ ), and Co records the largest increases in concentration for simultaneously heat-treated and corroded samples. This behavior emphasizes the high chemical stability of Co in the metal matrix of the analyzed alloys.

Based on the EDS analysis performed on different phases, following the initial values of Co and Cr content in those phases, the specific tendency of segregation and association of these elements to form common phases is observed on atoms distribution maps (see Fig. 2).

In the case of $\mathrm{Ni}_{1}(\mathrm{AlCrFeCoNi}) \mathrm{TT}$ sample, the chemical microanalysis on light grey phase indicates that it contains about 5.08 at\% $\mathrm{Al}, 9.14$ at\% Co, 31.76 at\% $\mathrm{Cr}, 29.80$ at $\% \mathrm{Fe}$ and 20.51 at $\% \mathrm{Ni}$. The dark grey phase contains 27 at \% Al, 8.55 at\% Co, 10.37 at\% Cr, 14.15 at\% Fe and 38.26 at\% Ni.

Regarding $\mathrm{Ni}_{1.4}\left(\mathrm{AlCrFeCoNi}_{1.4}\right)$ TT sample, the light grey phase contains 4.40 at $\% \mathrm{Al}, 7.16$ at $\% \mathrm{Co}, 34.18$ at $\% \mathrm{Cr}, 28.96$ at $\% \mathrm{Fe}$ and $21.42 \% \mathrm{Ni}$. The dark grey phase contains 23.53 at $\% \mathrm{Al}, 7.21$ at $\% \mathrm{Co}, 13.35$ at $\% \mathrm{Cr}$, 15.21 at $\% \mathrm{Fe}$ and 39.23 at $\% \mathrm{Ni}$. 


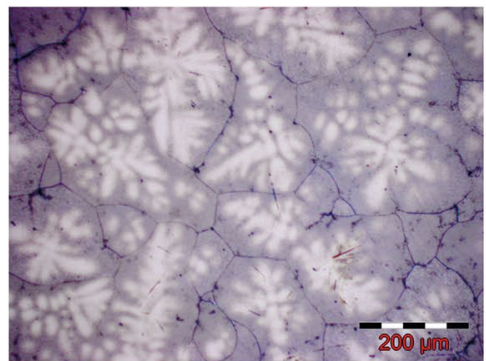

a)

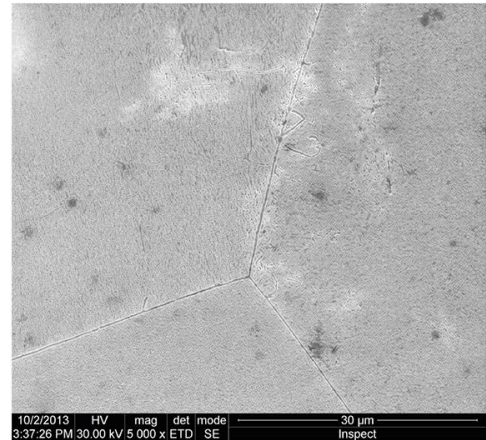

d)

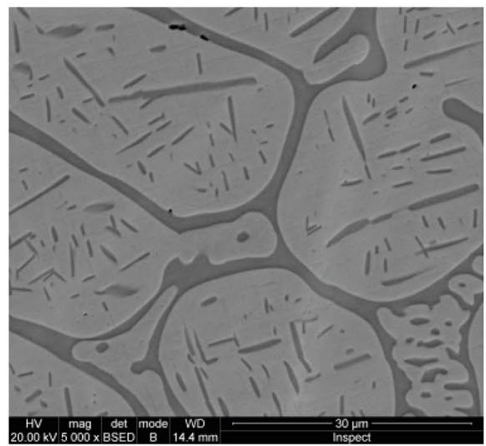

g)

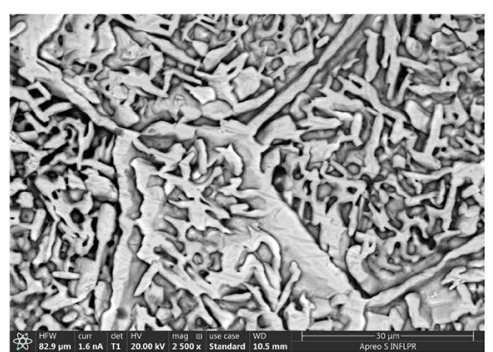

j)

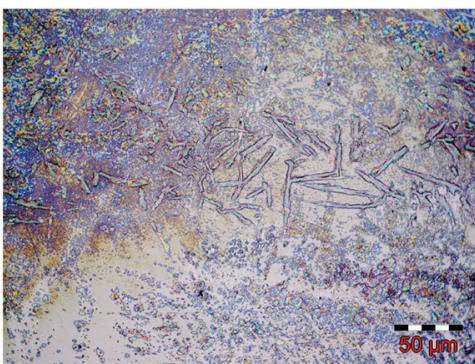

b)

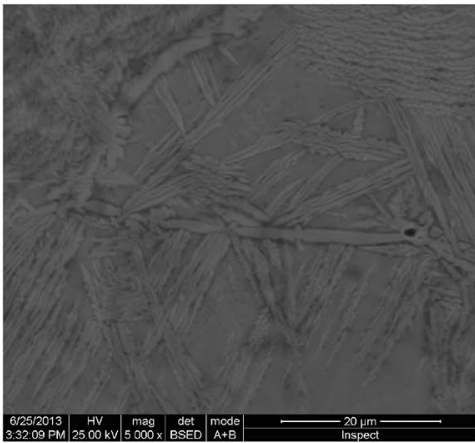

e)

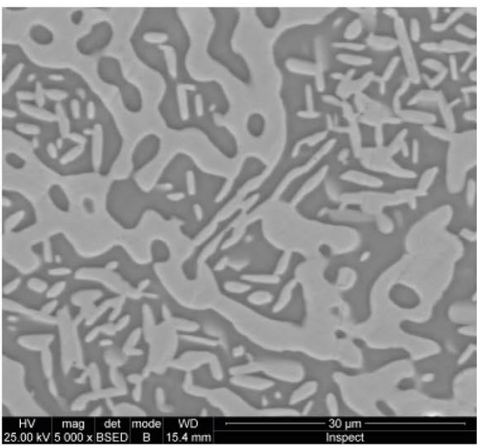

h)

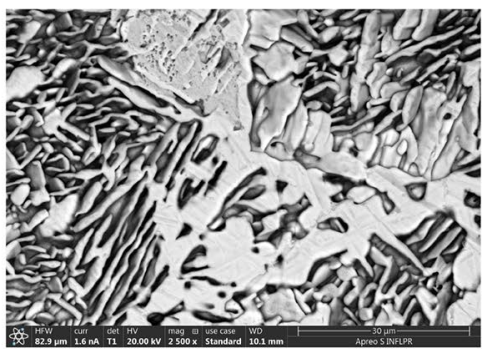

k)

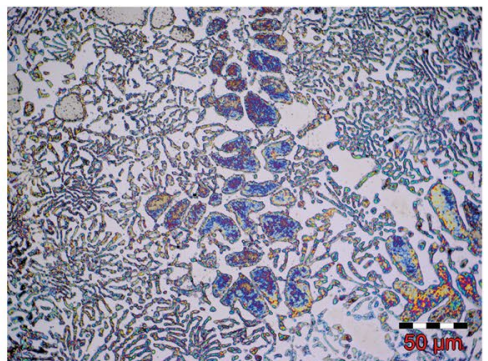

c)

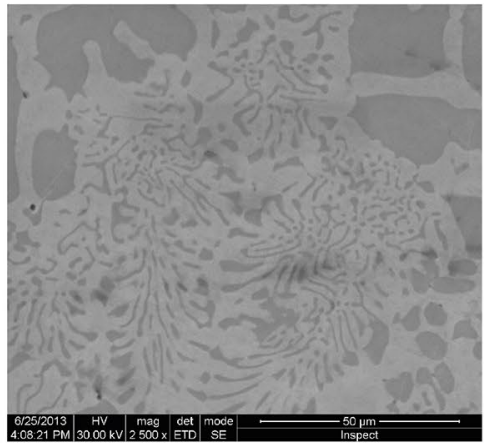

f)

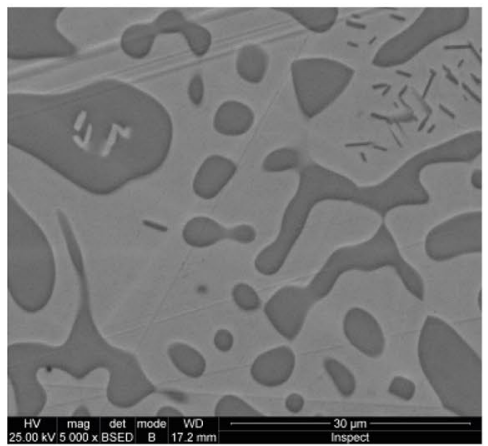

i)

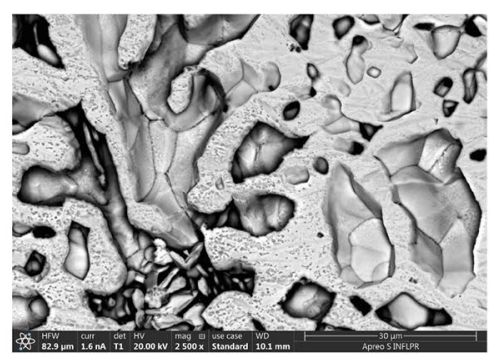

I)

Figure 1. Microstructure evolution of HEAs $\left(\mathrm{Ni}_{1}, \mathrm{Ni}_{1.4}\right.$ and $\left.\mathrm{Ni}_{1.8}\right)$ during thermal and chemical processing: (a), (b), (c) optical microstructure; (d), (e), (f) SEM as-cast microstructure; (g), (h), (i) SEM heat treated microstructure; (j), (k), (l) Thermal treated and corroded microstructure.

Finally, in the case of $\mathrm{Ni}_{1.8}\left(\mathrm{AlCrFeCoNi} i_{1.8}\right)$ TT sample, the light grey phase contains 21.73 at\% $\mathrm{Al}, 5.31$ at $\% \mathrm{Co}, 9.85$ at\% Cr, 12.82 at\% Fe and 48.88 at\% $\mathrm{Ni}$. The dark grey phase contains 5.51 at \% Al, 6.02 at \% Co, 29.06 at\% $\mathrm{Cr}, 24.98$ at.\% $\mathrm{Fe}$ and 31.01 at $\% \mathrm{Ni}$.

These results highlight the tendency of $\mathrm{Al}$ and $\mathrm{Ni}$ to form stable compounds (dark grey phase) and quite equal distribution of the other elements in light grey phase or in the acicular phases. 


\begin{tabular}{|c|c|c|c|c|c|c|c|c|c|}
\hline \multirow[b]{2}{*}{ Element } & \multicolumn{3}{|l|}{$\mathrm{Ni}_{1}$} & \multicolumn{3}{|l|}{$\mathrm{Ni}_{1.4}$} & \multicolumn{3}{|l|}{$\mathrm{Ni}_{1.8}$} \\
\hline & Corr & TT & $T+C$ & Corr & TT & $T+C$ & Corr & TT & $T+C$ \\
\hline $\mathrm{Al}$, at\% & 12.00 & 9.89 & 2.57 & 11.68 & 14.28 & 3.03 & 10.59 & 10.46 & 2.77 \\
\hline $\mathrm{wt} \%$ & 6.33 & 5.14 & 1.29 & 6.12 & 7.54 & 1.52 & 5.47 & 5.37 & 1.38 \\
\hline Error,\% & 5.47 & 5.43 & 4.13 & 2.84 & 5.47 & 5.74 & 2.92 & 5.82 & 5.76 \\
\hline Co, at $\%$ & 6.59 & 8.48 & 21.85 & 3.75 & 7.40 & 21.49 & 3.34 & 5.36 & 20.49 \\
\hline $\mathrm{wt} \%$ & 7.58 & 9.62 & 24.07 & 4.29 & 8.54 & 23.46 & 3.77 & 6.01 & 22.33 \\
\hline Error,\% & 5.34 & 5.02 & 1.79 & 3.32 & 4.43 & 1.79 & 3.88 & 4.51 & 1.76 \\
\hline $\mathrm{Cr}$, at $\%$ & 28.72 & 26.98 & 31.83 & 32.61 & 22.67 & 28.51 & 29.62 & 22.95 & 26.16 \\
\hline wt $\%$ & 29.17 & 27.01 & 30.93 & 32.93 & 23.07 & 27.46 & 29.50 & 22.71 & 25.15 \\
\hline Error, \% & 1.93 & 1.90 & 1.90 & 1.99 & 2.00 & 1.95 & 2.04 & 2.11 & 1.97 \\
\hline $\mathrm{Fe}$, at $\%$ & 26.56 & 26.40 & 26.41 & 24.75 & 21.52 & 23.52 & 22.94 & 21.39 & 21.07 \\
\hline wt $\%$ & 28.98 & 28.38 & 27.57 & 26.85 & 23.53 & 24.33 & 24.54 & 22.73 & 21.76 \\
\hline Error,\% & 2.05 & 1.95 & 1.87 & 1.81 & 2.11 & 1.94 & 1.90 & 2.30 & 1.99 \\
\hline $\mathrm{Ni}$, at\% & 23.28 & 24.99 & 12.73 & 24.78 & 31.13 & 19.62 & 31.33 & 37.68 & 25.14 \\
\hline $\mathrm{wt} \%$ & 26.58 & 28.24 & 13.97 & 28.26 & 35.78 & 21.33 & 35.24 & 42.10 & 27.29 \\
\hline Error,\% & 2.12 & 1.94 & 2.05 & 1.73 & 2.11 & 1.93 & 1.67 & 1.98 & 1.85 \\
\hline $\mathrm{O}, \mathrm{at} \%$ & 2.38 & 2.46 & 3.54 & 1.39 & 2.22 & 2.77 & 1.08 & 1.61 & 3.25 \\
\hline wt\% & 0.74 & 0.76 & 1.06 & 0.43 & 0.70 & 0.82 & 0.33 & 0.49 & 0.96 \\
\hline Error, \% & 5.15 & 4.57 & 4.13 & 2.78 & 5.21 & 4.40 & 2.73 & 6.24 & 4.28 \\
\hline
\end{tabular}

Table 1. EDS global analyses on micro areas for HEAs after different processing stages. Corr, corroded; TT, Thermal treated; $\mathrm{T}+\mathrm{C}$, Thermal treated and corroded.

X-ray diffraction. The XRD patterns acquired from as-cast samples are displayed in Fig. 3. The $\mathrm{Ni}_{1}$ sample exhibited a pure primitive cubic phase (space group Pm-3m, number 221), matched very well by reference pattern 04-018-5047, Al0.4Co0.4Cr0.4Fe0.4Ni0.4. Increasing the $\mathrm{Ni}$ content resulted in the appearance of a new FCC phase (Fm-3m, group 225, a =3.5643 $\AA$ ), that was matched by reference pattern 04-022-2301, $\mathrm{Co}_{0.25} \mathrm{Cr} 0.25 \mathrm{Fe}_{0.25} \mathrm{Ni}_{0.25}$ and indicated by symbol \# in front of the Miller indices in Fig. 3. Also, $\mathrm{Al}_{0.9} \mathrm{Ni}_{4.22}$ (pattern 00-050-1294) with a slightly different lattice parameter (FCC, $\mathrm{a}=3.5700 \AA$ ) and $\mathrm{Cr}_{0.10} \mathrm{Fe}_{0.65} \mathrm{Ni}_{0.25}$ (pattern 04-0192390) with a slightly different lattice parameter (FCC, $a=3.5920 \AA$ ) are good matches. The presence of an Al-Ni FCC type compound after the thermal treatment is strongly supported by the EDS results. After corrosion treatment, a strong decrease in $\mathrm{Ni}$ and $\mathrm{Al}$ concentrations was observed, which was probably caused by the dissolution of this compound, while the others elements were not that much affected. SEM images of the corroded surface also suggest that a phase initially present was dissolved and disappeared from the surface region.

XRD patterns acquired from samples after the thermal treatment exhibited a mixture of two cubic phases: a primitive one and a FCC one (Fig. 3), with the relative percentage displayed in Table 2, although the presence of other FCC type compounds as those mentioned above could not be ruled out. The patterns also displayed narrower diffraction peaks, indicative of grain growth. The lattice parameters of the Pm-3 $\mathrm{m}$ and FCC phases, also displayed in Table 2 did not significantly changed with the increase of Ni content or the thermal treatment.

With the increasing of nickel concentration, the lattice parameter of the primitive cubic phase varies very slightly, from $2.876 \AA$ to $2.870 \AA$, while the grain size remains almost the same (from 398 to 414 and $365 \AA$ ) for as-cast samples. For the FCC phase, the lattice parameters also vary very slightly but the grain size increases with the nickel content for both as-cast andannealed samples. It can be seen that, for all the studied alloys, the lattice parameter of the two phases varies marginally, which was also reported for other HEAs ${ }^{29}$.

The results show a good homogeneity of the samples with two main solid solutions formed and some minor compounds segregating in the dendritic zone.

After the thermal treatment, the elemental composition of HEAs does not change; however, after the corrosion stage, the $\mathrm{Al}$ concentration in the surface region significantly dropped, followed by $\mathrm{Ni}$; Co concentration went up, while $\mathrm{Fe}$ and $\mathrm{Cr}$ did not change much.

To explain these results, the formation after the thermal treatment of an Al-Ni compound is hypothesized, which should be corroded faster than the main HEA phase. There are several Al-Ni compounds having an FCC lattice and a lattice parameter very close to that of FCC AlCoCrFeNi HEA that could explain the results.

Open circuit potential (OCP). Open circuit potential measurement curves during one-week immersion are shown in Fig. 4.

For all analyzed HEAs, after a short immersion time of about some hours, there is an increase in the corrosion potential due to the growth of passive layers on the surface of the alloys. During the first $24 \mathrm{~h}$, the OCP for all the three alloys increases with $30-50 \mathrm{mV}$ due to the build-up of the passive layers on the surface of the HEAs. The maximum value of OCP is $236 \mathrm{mV}$ for $\mathrm{AlCrFeCoNi}$ and $235 \mathrm{AlCrFeCoNi}_{1.8}$ and almost half of this value, $102 \mathrm{mV}$, for $\mathrm{AlCrFeCoNi} i_{1.4}$. 

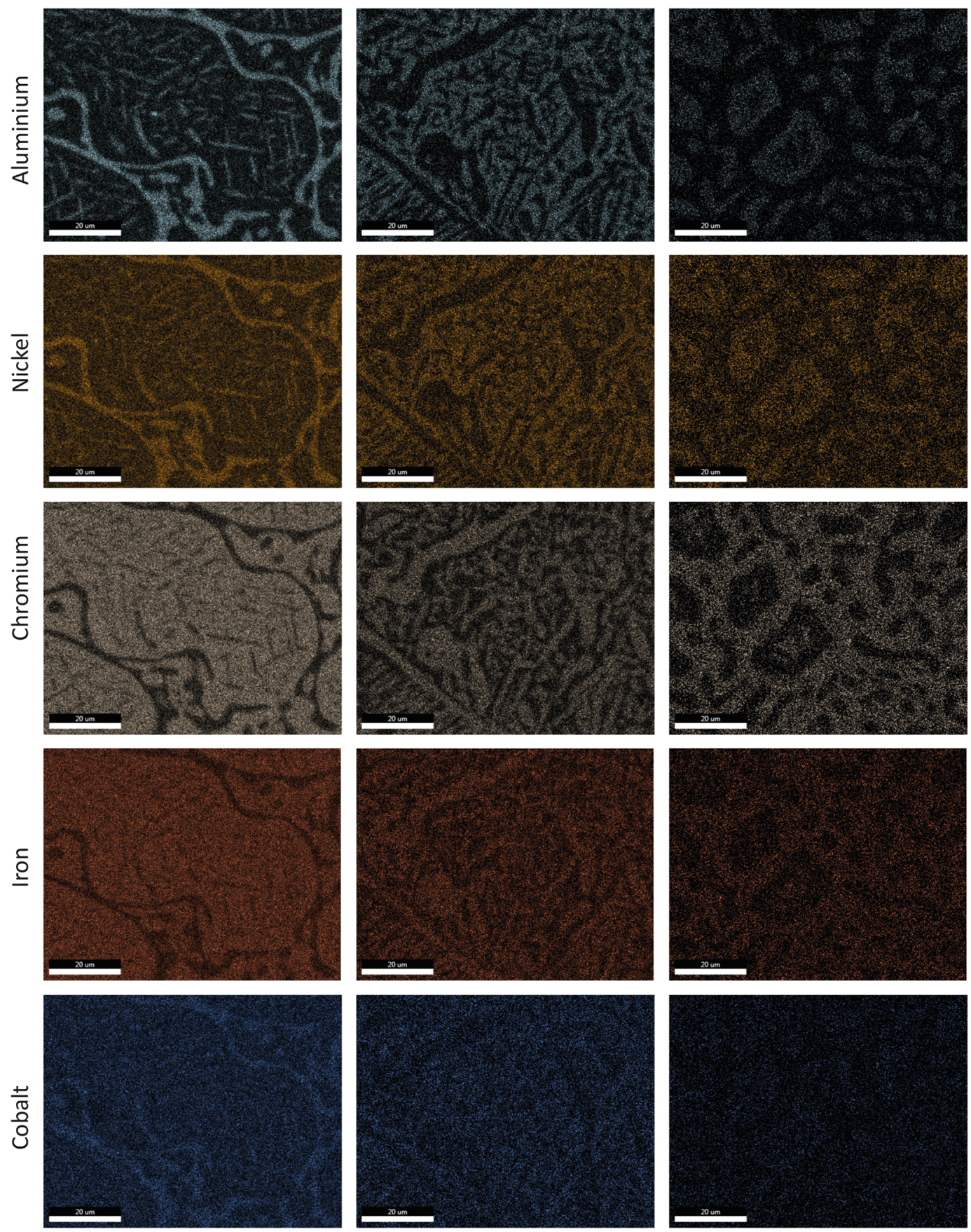

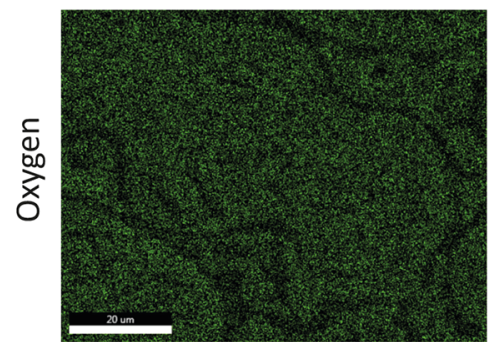

a)

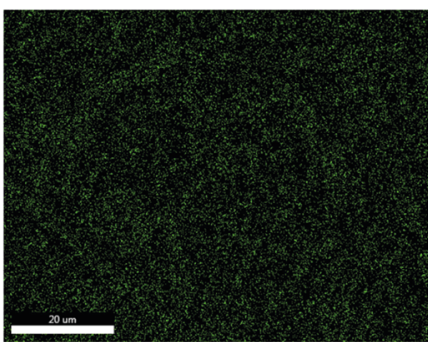

b)

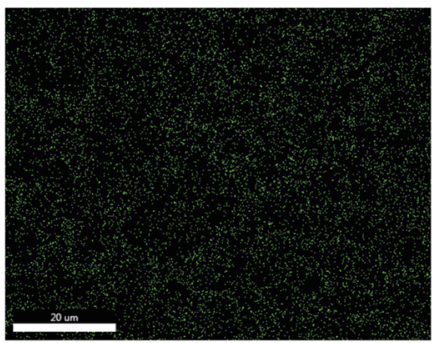

c)

Figure 2. Atoms distribution of main elements of HEAs micro-area. (a) in $\mathrm{Ni}_{1} \mathrm{TT}$ sample; (b) $\mathrm{Ni}_{1.4} \mathrm{TT}$ sample; (c) $\mathrm{Ni}_{1.8}$ TT sample. 


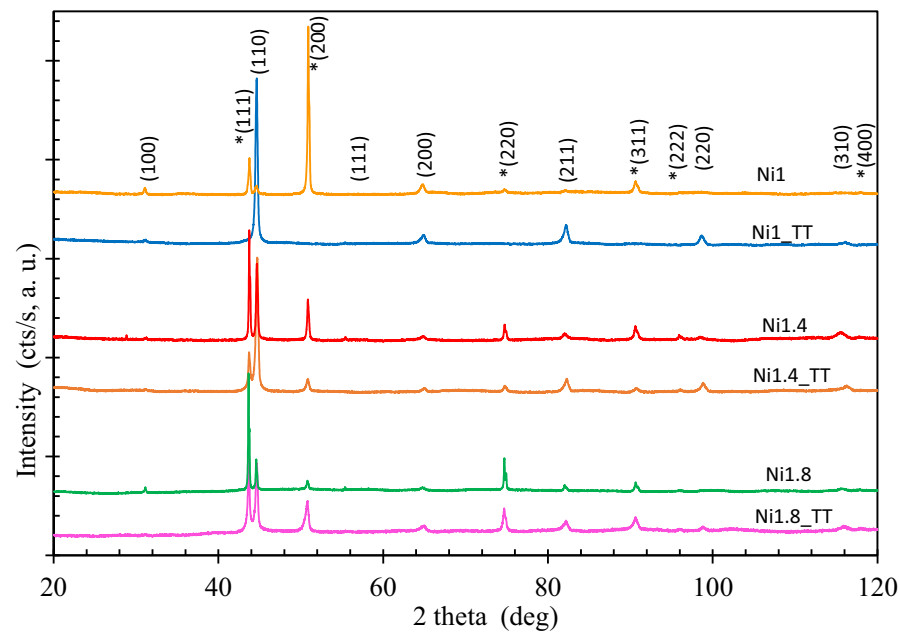

Figure 3. XRD patterns acquired from as-cast samples and from thermal treated samples (Miller indices for the new FCC phase induced by a higher Ni content are marked by symbol \#).

\begin{tabular}{|c|c|c|c|c|c|c|}
\hline \multirow[b]{2}{*}{ Sample } & \multicolumn{3}{|c|}{ Pm-3m (PDF 04-018-5047) } & \multicolumn{3}{|c|}{ Fm-3m (PDF 04-022-2301) } \\
\hline & Content (\%) & Lattice parameter $(\AA)$ & Grain size $(\AA)$ & Content (\%) & Lattice parameter $(\AA)$ & Grain size $(\AA)$ \\
\hline $\mathrm{Ni}_{1}$ & 100 & 2.876 & 398 & - & - & - \\
\hline $\mathrm{Ni}_{1.4}$ & 78 & 2.870 & 414 & 22 & 3.595 & 327 \\
\hline $\mathrm{Ni}_{1.8}$ & 37 & 2.873 & 365 & 63 & 3.599 & 402 \\
\hline $\mathrm{Ni}_{1-} \mathrm{TT}$ & 16 & 2.875 & 574 & 84 & 3.588 & 562 \\
\hline $\mathrm{Ni}_{1.4 \_} \mathrm{TT}$ & 73 & 2.871 & 937 & 27 & 3.591 & 1813 \\
\hline $\mathrm{Ni}_{1.8 \_} \mathrm{TT}$ & 75 & 2.872 & 1258 & 25 & 3.591 & 1259 \\
\hline
\end{tabular}

Table 2. Samples phase composition, lattice parameters and grain size.

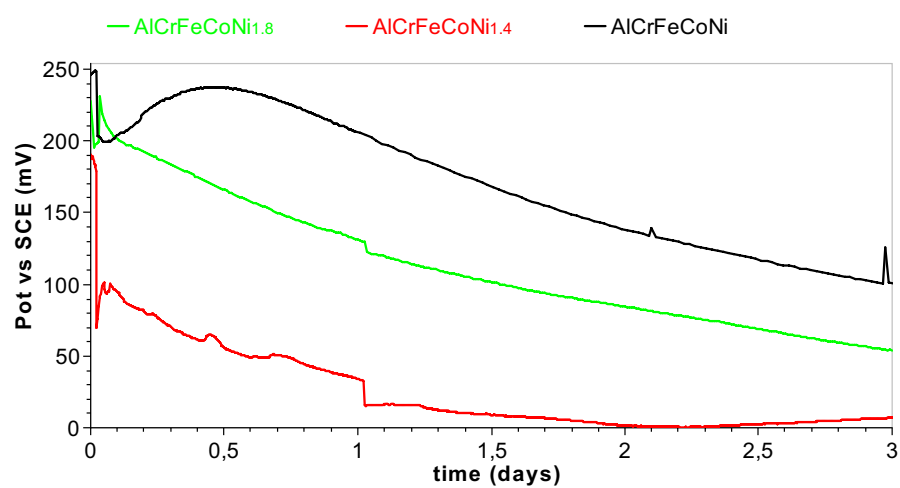

Figure 4. Variation of open circuit potential with time for the three alloys ( $\mathrm{AlCrFeCoNi}, \mathrm{AlCrFeCoNi}{ }_{1.4}$, $\left.\mathrm{AlCrFeCoNi} i_{1.8}\right)$ in Ringer solution.

After the OCP reaches the maximum value, it begins to decrease. This decrease is due to the changes in the characteristics of the surface film.

From the curves can be seen continuous breakages and repairs of the passive layer.

Potentiodynamic polarization result. Polarization techniques have been used respecting the indications of ASTM Subcommittee G01.11 on Electrochemical Measurements in Corrosion Testing regarding the reproducibility of cyclic potentiodynamic polarization measurements for determining the susceptibility to localized corrosion $^{30}$. 


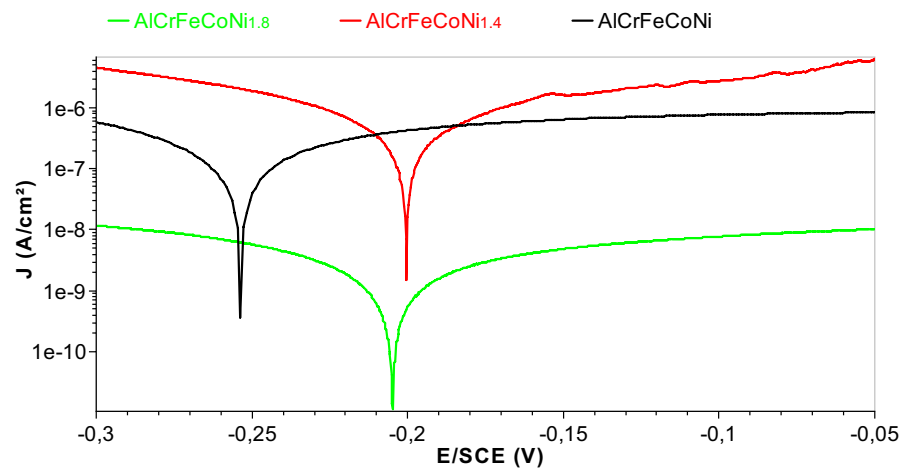

a)

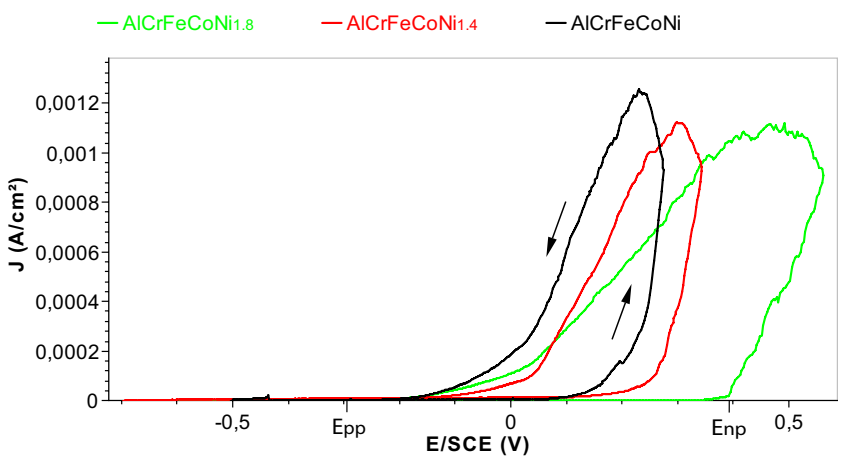

b)

Figure 5. (a) Tafel curves for $\mathrm{AlCrFeCoNi}, \mathrm{AlCrFeCoNi}_{1.4}$ and $\mathrm{AlCrFeCoNi}_{1.8}$ after one-week immersion. (b) Potentiodynamic polarization curves for $\mathrm{AlCrFeCoNi}, \mathrm{AlCrFeCoNi}{ }_{1.4}, \mathrm{AlCrFeCoNi}_{1.8}$ presented in linear axis in order to reveal the nucleation pitting potential and pitting protection potential).

\begin{tabular}{|l|l|l|l|l|l|}
\hline Alloy & $\mathbf{E}_{\text {corr }}(\mathbf{m V})$ & $\mathbf{i}_{\text {corr }}\left(\mathbf{n A} / \mathbf{c m}^{2}\right)$ & $\mathbf{b}_{\mathbf{a}}(\mathbf{m V})$ & $\mathbf{b}_{\mathbf{c}}(\mathbf{m V})$ & Corrosion rate (mmpy) \\
\hline $\mathrm{AlCrFeCoNi}$ & -255.59 & 428 & 638.4 & 255.1 & $5.92 \mathrm{E}-03$ \\
\hline $\mathrm{AlCrFeCoNi}_{1.4}$ & -199.7 & 748 & 169.2 & 124.5 & $3.00 \mathrm{E}-02$ \\
\hline $\mathrm{AlCrFeCoNi}_{1.8}$ & -206.86 & 374 & 347 & 185.8 & $1.25 \mathrm{E}-02$ \\
\hline
\end{tabular}

Table 3. Electrochemical parameters of corrosion process estimated through Tafel approximation.

1. Plots in a semi-logarithmic version between $-150 \mathrm{mV}$ (vs OCP) and $+150 \mathrm{mV}$ (vs OCP) after 1 week in Ringer solution are displayed (see Fig. 5a).

The values of $\mathrm{E}_{\text {corr }}, \mathrm{i}_{\text {corr }}, \mathrm{b}_{\mathrm{a}}, \mathrm{b}_{\mathrm{c}}$ and $\mathrm{V}_{\text {corr }}$ were determined by EC-Lab software and presented in Table 3 . An alloy will corrode if $b_{c}$ is greater than $b_{a}$ and will be subjected to passivity if $b_{c}$ is smaller than $b_{a}$. The higher values of $b_{a} v s b_{c}$ for all the three alloys indicates an anodic control of the corrosion process which implies the existence of a passive layer on the sample's surface. The point resulted in the intersection of the two Tafel slopes has the coordinates $i_{\text {corr }}$ and ZCP (zero current potential). It can be seen that in all the cases, the difference between OCP and ZCP is only few $\mathrm{mV}$. This indicates that the errors introduced into the values of kinetic parameters are negligible with the variations of the charging current.

The corrosion current densities obtained for the analyzed HEAs are much lower than that of the $304 \mathrm{SS}^{31}$, which means that these HEAs are more resistant to general corrosion than 304SS.

With the increase of $\mathrm{Ni}$ content, the corrosion rate of the alloy presents a non-linear trend mainly due to the fact that Ni content is not the only factor affecting the corrosion process (for example: microstructure, element distribution, etc.).

2. Pitting potential

The pitting potential (or pit nucleation potential $\mathrm{E}_{\mathrm{np}}$ ) is one of the most important parameter characterizing the susceptibility of HEA to pitting corrosion. It is the potential at which the passive film formed on the HEA surface is damaged and the current density begins to increase drastically in the passive range due to the pits nucleations. Plots in a linear version of I vs E between $-0.8 \mathrm{~V}$ and $+0.5 \mathrm{~V}$ vs Ref (see Fig. $5 \mathrm{~b}$ ) were performed in order to determine the pit nucleation potential (pitting potential) and pitting protection potential (the potential in the reverse scan associated with a drop in current density caused by the repasivation of pits). 
A scan rate of $1 \mathrm{mV} / \mathrm{s}$ was used and considered to be sufficiently slow to prevent any distortion of the curves. The values of nucleation pitting potential were $185 \mathrm{mV}$ for $\mathrm{AlCrFeCoNi}, 245 \mathrm{mV}$ for $\mathrm{AlCrFeCoNi}{ }_{1.4}$ and $385 \mathrm{mV}$ for $\mathrm{AlCrFeCoNi}_{1.8}$. The obtained values characterize the resistance of the analyzed HEA to pitting corrosion and can therefore be considered a measure of the susceptibility of HEA in simulated body fluid. AlCrFeCoNi ${ }_{1.8}$ has the most positive pit nucleation potential: the more positive Enp, the more resistant the alloy is to pitting.

Among the three tested alloys, the difference between $\mathrm{E}_{\mathrm{np}}$ and $\mathrm{E}_{\mathrm{pp}}$ for $\mathrm{AlCrFeCoNi}_{1.8}$ is the largest, which suggests that the repasivation tendency of pits on this alloy is large and only at higher potential these pits can transform to stable pits.

Microhardness. Five indentations have been made for each sample and the average value was calculated. The hardness values decrease with the increase of nickel concentration $(562 \mathrm{HV}$ for AlCrFeCoNi, $455 \mathrm{HV}$ for $\mathrm{AlCrFeCoNi}_{1.4}$ and $316 \mathrm{HV}$ for $\mathrm{AlCrFeCoNi} i_{1.8}$ ) as a result of dissolution of $\mathrm{Cr}$ and Fe precipitates in the nickelrich matrix, forming a stable solid solution as we reported before ${ }^{10}$. For other HEA system, substitution of $\mathrm{Al}$ with different $\mathrm{Zr}$ concentrations, determine changes in the microhardness values, attributed to the phase changes in the alloy structure ${ }^{23}$.

As has been demonstrated in a few studies ${ }^{11,24}$ most metals and alloys exhibit strengthening effect by grain refinement due to the boundaries that function as impediments to dislocations. The decreasing of grain boundary density lead to the microhardness (and equivalent yield strength) values decreasing in HEAs which is consistent with the concept that the lattice of the crystal is seriously distorted and dislocations movement is more difficult than in conventional alloys ${ }^{32,33}$.

\section{Conclusions}

In this study, the effects of nickel content on the microstructure, microhardness and corrosion behavior of high-entropy entropy $\mathrm{AlCoCrFeNi}_{\mathrm{x}}$ alloys in simulated body fluid were investigated and following conclusions were drawn:

1. The microscopy examination revealed the dendritic morphology for as cast alloy $\mathrm{AlCrFeCoNi}_{1.0}$ and the increase of the extent of the interdendritic areas by increasing the nickel concentration for $\mathrm{AlCrFeCoNi}_{1.4}$ and $\mathrm{AlCrFeCoNi} \mathrm{N}_{1.8}$. The annealing determined a more uniform distribution of the phases for the three high-entropy alloys and the modification of the morphology of the grain boundaries. It also resulted in a significant increase of the grain sizes.

2. The formation after the annealing treatment of an Al-Ni compound is hypothesized, which should be corroded faster than the main HEA phase. There are several Al-Ni compounds having an FCC lattice and a lattice parameter very close to that of FCC AlCoCrFeNi.

3. The low corrosion rates and low corrosion currents demonstrate the good stability of the studied samples of $\mathrm{AlCoCrFeNi}_{\mathrm{x}}(\mathrm{x}=1.0,1.4$ and 1.8) in simulated biological environment.

4. The lattice parameter of the cubic phase varies very slightly, from 2876 to $2870 \AA$ by increasing the Ni content, but the grain size decreases considerably (from 398 to $206 \AA$ ) for as-cast samples. For the FCC phase, the lattice parameters also vary very slightly but the grain size increases with the nickel content for both as-cast and annealing samples.

5. The results proved that by manipulating the composition and structure of HEAs their mechanical and chemical performance could be optimized to meet the requirements for their usage as novel medical instruments materials.

\section{Data availability}

The datasets generated during the current study are available from the corresponding author on reasonable request.

Received: 4 June 2020; Accepted: 17 November 2020

Published online: 03 December 2020

\section{References}

1. Yeh, J. W. \& Lin, S. J. Breakthrough applications of high-entropy materials. J. Mater. Res. 33, 3129-3137 (2018).

2. Zhang, Y. High-Entropy Materials A Brief Introduction. https://doi.org/10.1007/978-981-13-8526-1 (2019).

3. Ching, W. Y. et al. Fundamental electronic structure and multiatomic bonding in 13 biocompatible high-entropy alloys. $n p j$ Comput. Mater. 6, 1-10 (2020).

4. Zhang, C. et al. Understanding phase stability of Al-Co-Cr-Fe-Ni high entropy alloys. Mater. Des. 109, 425-433 (2016).

5. Csaki, I. et al. Researches regarding the processing technique impact on the chemical composition, microstructure and hardness of AlCrFeNiCo high entropy alloy. Rev. Chim. 67, 1373-1377 (2016).

6. Yeh, J. W. et al. Nanostructured high-entropy alloys with multiple principal elements: Novel alloy design concepts and outcomes. Adv. Eng. Mater. 6, 299-303+274 (2004).

7. Wang, Y. P., Li, B. S., Ren, M. X., Yang, C. \& Fu, H. Z. Microstructure and compressive properties of AlCrFeCoNi high entropy alloy. Mater. Sci. Eng. A 491, 154-158 (2008).

8. Ye, Y. F., Wang, Q., Lu, J., Liu, C. T. \& Yang, Y. High-entropy alloy: challenges and prospects. Mater. Today 19, 349-362 (2016).

9. Alabd Alhafez, I., Ruestes, C. J., Bringa, E. M. \& Urbassek, H. M. Nanoindentation into a high-entropy alloy-an atomistic study. J. Alloys Compd. 803, 618-624 (2019).

10. Voiculescu, I., Geanta, V., Stefanoiu, R., Patrop, D. \& Binchiciu, H. Influence of the chemical composition on the microstructure and microhardness of alcrfeconi high entropy alloy. Rev. Chim. 64, 1441-1444 (2013). 
11. Li, Z., Zhao, S., Ritchie, R. O. \& Meyers, M. A. Mechanical properties of high-entropy alloys with emphasis on face-centered cubic alloys. Prog. Mater. Sci. 102, 296-345 (2019).

12. Chen, C., Pang, S., Cheng, Y. \& Zhang, T. Microstructure and mechanical properties of. J. Alloys Compd. 659, 279-287 (2016).

13. Yang, S., Liu, Z. \& Pi, J. Microstructure and wear behavior of the AlCrFeCoNi high-entropy alloy fabricated by additive manufacturing. Mater. Lett. 261, 127004 (2020).

14. Chen, J. et al. A review on fundamental of high entropy alloys with promising high-temperature properties. J. Alloys Compd. 760, $15-30$ (2018).

15. Miracle, D. B. \& Senkov, O. N. A critical review of high entropy alloys and related concepts. Acta Mater. 122, 448-511 (2017).

16. Shon, Y., Joshi, S. S., Katakam, S., Shanker Rajamure, R. \& Dahotre, N. B. Laser additive synthesis of high entropy alloy coating on aluminum: corrosion behavior. Mater. Lett. 142, 122-125 (2015).

17. Li, Q. H., Yue, T. M., Guo, Z. N. \& Lin, X. Microstructure and corrosion properties of alcocrfeni high entropy alloy coatings deposited on AISI 1045 steel by the electrospark process. Metall. Mater. Trans. A Phys. Metall. Mater. Sci. 44, 1767-1778 (2013).

18. Zhou, P. F., Xiao, D. H. \& Yuan, T. C. Microstructure, mechanical and corrosion properties of AlCoCrFeNi high-entropy alloy prepared by spark plasma sintering. Acta Metall. Sin. (English Lett.) 33, 937-946 (2020).

19. Yamanaka, K. et al. Corrosion mechanism of an equimolar AlCoCrFeNi high-entropy alloy additively manufactured by electron beam melting. npj Mater. Degrad. 4, 1-12 (2020).

20. Shi, Y. et al. Homogenization of AlxCoCrFeNi high-entropy alloys with improved corrosion resistance. Corros. Sci. 133, 120-131 (2018).

21. Shi, Y. et al. Corrosion of $\mathrm{Al} \times \mathrm{CoCrFeNi}$ high-entropy alloys : Al-content and potential scan-rate dependent pitting behavior. Eval. Program Plann. 119, 33-45 (2017).

22. Chen, H. Y. et al. Effect of the substitution of Co by Mn in Al-Cr-Cu-Fe-Co-Ni high-entropy alloys. Ann. Chim. Sci. Mater. 31, 685-698 (2006).

23. Feng, X. et al. Effect of $\mathrm{Zr}$ addition on microstructure and mechanical properties of CoCrFeNiZrx high-entropy alloy thin films. Appl. Nanosci. https://doi.org/10.1007/s13204-019-01057-7 (2019).

24. Huang, Y. C., Su, C. H., Wu, S. K. \& Lin, C. A study on the hall-petch relationship and grain growth kinetics in FCC-structured high/medium entropy alloys. Entropy 21, 297 (2019).

25. Geanta, V., Voiculescu, I., Vizureanu, P. \& Victor Sandu, A. High entropy alloys for medical applications. Eng. Steels High Entropy Alloys https://doi.org/10.5772/intechopen.89318 (2020).

26. Qiu, Y. et al. Corrosion characteristics of high entropy alloys corrosion characteristics of high entropy alloys. Mater. Sci. Technol. 31, 1235-1243 (2015).

27. Guérin, M. et al. Identification of the metallurgical parameters explaining the corrosion susceptibility in a 2050 aluminium alloy. Corros. Sci. 102, 291-300 (2016).

28. Cao, L. et al. Microstructural evolution, phase formation and mechanical properties of multi-component AlCoCrFeNix alloys. Appl. Phys. A Mater. Sci. Process. 125, 1-11 (2019).

29. Krapivka, N. A., Firstov, S. A., Karpets, M. V., Myslivchenko, A. N. \& Gorban, V. F. Features of phase and structure formation in high-entropy alloys of the AlCrFeCoNiCux system (x = 0, 0.5, 1.0, 2.0, 3.0). Phys. Met. Metallogr. 116, 467-474 (2015).

30. Baboian R. \& Haynes, S. G. Cyclic polarization measurements-experimental procedure and evaluation of test data. https://doi. org/10.1520/STP28038S (1981).

31. Chen, Y. Y., Duval, T., Hung, U. D., Yeh, J. W. \& Shih, H. C. Microstructure and electrochemical properties of high entropy alloys-a comparison with type-304 stainless steel. Corros. Sci. 47, 2257-2279 (2005).

32. Liu, W. H., Wu, Y., He, J. Y., Nieh, T. G. \& Lu, Z. P. Grain growth and the Hall-Petch relationship in a high-entropy FeCrNiCoMn alloy. Scr. Mater. https://doi.org/10.1016/j.scriptamat.2012.12.002 (2013).

\section{Acknowledgements}

The research was supported by the Romanian National Authority, Executive Agency for Higher Education, Research, Development and Innovation (CNCS CCDI-UEFISCDI), project number PN-III-P1-1.2-PCCDI2017-239/60PCCDI and Romanian National Nucleu Program LAPLAS VI - contract nº. 16N/2019.

\section{Author contributions}

M. López Ríos-Conceptualization, methodology, writing-original draft preparation, investigation. P. Socorro Perdomo-data curation (Figs. 4, 5 and Table 3). V. Geanta-investigation, Figs. 1, 2 and Table 1, resources. I. Voiculescu-investigation (Figs. 1, 2, Table 1), data curation, writing-review and editing. V. Craciun-investigation (Fig. 3 and Table 2), data curation, writing - review and editing. I. Boerasu -investigations. J.Mirza Rosca: data curation, project administration, visualization, writing-review and editing (data curation, supervision, validation of data). All authors reviewed the manuscript and agreed to the published version of the manuscript.

\section{Competing interests}

The authors declare no competing interests.

\section{Additional information}

Correspondence and requests for materials should be addressed to J.C.M.R.

Reprints and permissions information is available at www.nature.com/reprints.

Publisher's note Springer Nature remains neutral with regard to jurisdictional claims in published maps and institutional affiliations. 
(c) (i) Open Access This article is licensed under a Creative Commons Attribution 4.0 International cc) License, which permits use, sharing, adaptation, distribution and reproduction in any medium or format, as long as you give appropriate credit to the original author(s) and the source, provide a link to the Creative Commons licence, and indicate if changes were made. The images or other third party material in this article are included in the article's Creative Commons licence, unless indicated otherwise in a credit line to the material. If material is not included in the article's Creative Commons licence and your intended use is not permitted by statutory regulation or exceeds the permitted use, you will need to obtain permission directly from the copyright holder. To view a copy of this licence, visit http://creativecommons.org/licenses/by/4.0/.

(C) The Author(s) 2020 